\title{
CRÍTICA DE "LA ÉPOCA" AL SENSACIONALISMO AMERICANO
}

\section{CRITICISM OF "LA ÉPOCA" SENSATIONALISM AMERICAN}

\section{AUTOR}

Isabel Tajahuerce

Facultad de Ciencias de la Información. Universidad Complutense de Madrid.

isabel.tajahuerce@yahoo.es

\section{RESUMEN}

La prensa sensacionalista, conocida como periodismo "amarillo", fue el desencadenante de la guerra entre Estados Unidos y España. Los intereses económicos y políticos priman por encima de los informativos, y esto significa una desinformación periodística mediante la cual se nutre la población creando así una imagen errónea de los participantes en la guerra.

\section{PALABRAS CLAVE}

Sensacionalismo - Prensa - Guerra - España - EEUU

\section{ABSTRACT}

The tabloid journalism known as "yellow" was the trigger for war between the U.S. and Spain. Economic and political interests take precedence over the news, and this is a journalistic disinformation which is nourished by people creating a false image of the participants in the war.

\section{KEY WORDS}

Sensationalism - Press - War - Spain - USA 


\section{ÍNDICE}

1. La explosión del Maine

2. La guerra y la responsabilidad de la prensa "amarilla"

La prensa sensacionalista americana fue, en parte, responsable de la guerra entre España y los Estados Unidos en 1898. El World y el Journal -y en menor medida otros periódicos- manipularon sin escrúpulos a sus lectores, convirtiendo a la verdad en la primera víctima de la guerra aun antes de que ésta fuese una realidad. Todo servía para crear una opinión pública favorable al conflicto: exagerar, tergiversar, mentir... Los intereses económicos y políticos se impusieron a los informativos, y el periodismo demostró su fuerza como arma de propaganda.

Los periódicos españoles denunciaron la irresponsabilidad de la prensa sensacionalista antes, durante, y después de la guerra. Pero ellos tampoco fueron ejemplo de fidelidad a la verdad y respeto a los lectores. En principio fueron moderados y la mayoría se opuso a la guerra, pero cuando esta fue un hecho -salvo los órganos de socialistas y republicanos federales- adoptaron una postura triunfalista y ocultaron la verdad a sus lectores. Parte de su campaña de propaganda se basó en demostrar que los periódicos americanos -preocupados sólo por el beneficio económico- eran los responsables directos de la guerra. Así se comportó el diario conservador La Época.

\section{La explosión del Maine.}

Las mentiras que sobre España y la situación en Cuba publican los periódicos de Hearst y Pulitzer -y algunos otros- no ocupan en principio mucho espacio en $L a$ Época, ya que este periódico prefiere resaltar la opinión de publicaciones más "sensatas", por ejemplo la del Evening Post que dice que: 
"la nación ni busca la guerra, ni teme que país alguna la provoque, y que mientras el país piense y sienta así, es inútil esperar que el Congreso destine cantidades desproporcionadas de sus ingresos para armamentos"1.

La explosión del Maine cambia las cosas. En un primer momento parece que un sector amplio de la prensa norteamericana demuestra prudencia a la hora de opinar sobre lo ocurrido, aunque reconoce al mismo tiempo que la situación es muy delicada, mientras otros lanzan ya la idea de que no ha sido un accidente. Entre los primeros se encuentran el New York Times y el Herald, y entre los segundos el World y el Journal ${ }^{2}$.En cuanto al Evening Post, al que antes La Época llamaba "sensato" y ahora "filibustero", admite la posibilidad del atentado. Estos periódicos y algunas "entidades" están empeñados en provocar un conflicto internacional, aunque:

"Ocupándose el corresponsal en Washington del Daily News de la agitación belicosa que tratan de crear los elementos jingoes $y$ laborantes, dice que existen en los Estados Unidos algunos casos esporádicos de fiebre bélica contra España, porque los jingoes no han trabajado en balde. Pero tales casos están aislados por el sentido común, que nunca se echa de menos en esta educada democracia siempre que llegan circunstancias críticas" ${ }^{3}$.

La Época no desea la guerra y acusa a los periódicos sensacionalistas que aprovechan un trágico accidente para

"extraviar la opinión, llevando al ánimo del público los rumores más absurdos y más contrarios a la verdad, con objeto de hacerle creer

\footnotetext{
${ }^{1}$ Cuyás y Armengol, Antonio. "Los Estados Unidos quieren la Paz", La Época, 16 de febrero de 1898.

2 "J uicios de la prensa sobre la voladura del Maine...". La Época, 18 de febrero de 1898.

3 "La voladura del Maine. Manejos de los jingoes". La Época, 20 de febrero de 1898.
} 
que la catástrofe del Maine se debió a un atentado exterior"4;

y muestra abiertamente su indignación por las falsedades publicadas en el World, por sus "grabados tremebundos en los que la fantasía del dibujante ha echado el resto", y porque no hay ni una frase de reconocimiento para los marinos españoles que heroicamente rescataron a los naufragos del Maine ${ }^{5}$.

También llama a la calma, intentando demostrar que no existen razones para creer que la guerra es algo inevitable, pues no todos los americanos opinan igual. Para ello, reproduce parte de un artículo contrario a la guerra publicado en la revista Harpers Weekly y que termina de la siguiente manera:

"Siendo la ambición de la paz el temperamento de un pueblo de sentimientos elevados, los malhechores que, con sus falsas noticias y llamamientos sin escrúpulos a las bajas pasiones, al encono y al odio, llevan a una nación a la guerra, sólo merecen la execración de todo hombre honrado $y$, por lo tanto, se debe a los que gobiernan una inmensa gratitud cuando consideran como el más alto concepto del deber evitar al pueblo los horrores de la guerra mientras la paz pueda mantenerse honrosamente" 6 .

No obstante, la situación es crítica y no hay que mostrarse demasiado optimista. Hay muchos intereses en juego, y eso hay que tenerlo presente:

"Hay en el verdadero pueblo norteamericano un fondo respetable de buen sentido y de equidad: la prensa yellow encuentra quien la diga sendas verdades sobre su mercantilismo y la desprecie (...) pero la complicidad de muchos elementos hostiles a España por la

\footnotetext{
4 "La prensa jingoista y la explosión del "Maine"". La Época, 5 de marzo de 1898

5 "La avalancha amarilla". La Época. 15 de marzo de 1898

6 "En pro de la paz", La Época, 26 de marzo de 1898
} 
ignorancia o por motivos de política interior, hace que sea realmente peligroso para las relaciones pacíficas entre ambos estados el momento a que nos referimos" 7 .

\section{La guerra y la responsabilidad de la prensa "amarilla".}

Pronto la guerra será una realidad. Entonces llega el momento de resaltar que la superioridad de los Estados Unidos no es tal: ni han atacado Puerto Rico, ni Manila y la escuadra de Cayo Hueso ha capturado algunos buques mercantes contradiciendo "las declaraciones de MacKinley, de que se daría un plazo a los buques españoles que no estuvieran advertidos de la guerra", mientras el Mongrove intenta incomunicar a Cuba con la metrópoli. Esto último impedirá a los españoles obtener información directa de la isla y los americanos podrían transmitir informaciones falsas, por eso hay que tener mucho cuidado:

"La interrupción del cable, aunque sea pasajera, producirá aquí alguna perturbación, pero si hay serenidad en el espiritu público, no conseguirán su objetivo los norteamericanos, pues claro es que las noticias de procedencia yankee que vengan estando interrumpida la comunicación con Cuba serán indudablemente sospechosas" ${ }^{\prime}$.

Desde que la guerra es un hecho La Época acusa a los periódicos sensacionalistas de ser directamente responsables del conflicto porque mintieron, excitaron las pasiones y "finalmente" empujaron al presidente a que "cometiera la brutal iniquidad". Pero ya lo están pagando, según el diario español, ya que esa guerra que tanto deseaban no les ha reportado los beneficios esperados. Su objetivo era sólo ganar dinero y están gastando mucho y ganando poco, mientras se lamentan con cinismo:

"La guerra -dicen- no nos tiene en cuenta; la gente no responde a

\footnotetext{
7 "Paz armada", La Época, 15 de marzo de 1898.

8 "Ecos del día", La Época, 25 de abril de 1898
} 
nuestros esfuerzos; si esto dura, nos arruinamos. Venga la paz y ya caerán algunos crímenes o tal o cual escándalo que con menos gastos nos rendirán mayores productos que los que ahora obtenemos" 9 .

Cuando termine la guerra reconocerá -en una escueta nota- que, aunque los gastos de la prensa americana han sido muchos, también lo han sido los beneficios: tuvieron que pagar sueldos elevados a los corresponsales, asegurar sus vidas, fletar una escuadrilla que quemaba todos los días muchas toneladas de carbón, pagar a la tripulación y enviar despachos a Nueva York que costaban alrededor de 2.000 dólares diarios, "pero han ganado sumas importantes, pues ha habido periódico que público diez o doce números extraordinarios cada día" ${ }^{10}$.

Pero ya llegará el momento de aceptar la realidad. Durante la guerra La Época tiene un objetivo: desprestigiar todo lo posible a la prensa americana. Por eso insiste en la responsabilidad de los periódicos "amarillos" en el conflicto, comentando qué publicaciones serias del extranjero atribuyen a la campaña de éstos el origen de la guerra. Las críticas se centran especialmente en Pulitzer y Hearst "muy desacreditados ambos, pero que ejercen, a pesar de todo, una infuencia decisiva en las grandes masas de la opinión". Para dar idea de la falta de escrúpulos de ambos, incluye algunos datos biográficos:

Pulitzer, dice, es "un judío ruso" que llegó a los dieciocho años a América y "obtuvo la mayor prima que se concedía por alistamiento durante la guerra de secesión". Fue cochero, mozo de café "y entre carrera y carrera y servicio y servicio estudió la carrera de derecho", en San Luis "debutó como abogado" y compró dos periódicos, pero tuvo que emigrar porque un coronel "que había ido a pedirle reparación de ciertas calumnias, fue asesinado en las oficinas del periódico". En Nueva York compró el World y repetía a sus colaboradores: "jamás os olvidéis de que no pido

\footnotetext{
${ }^{9}$ Zeda. "Crónicas contemporáneas. La prensa y la guerra". La Época, 25 de agosto de 1898.

10 "Los gastos de la prensa americana", La Época. 25 de agosto de 1898.
} 
más que tres cosas: ideas, ideas e ideas", esas ideas -por supuesto- eran sólo aquellas que podían aumentar la tirada del periódico, lo único que importaba a su propietario que envió a muchos "desgraciados" a la cárcel, aun cuando su culpabilidad fuera dudosa.

Con Hearst se muestra menos duro. Comenta que es hijo de un senador millonario, que tuvo un periódico en San Francisco y que compró el Journal a un hermano de Pulitzer "que lleno de amor fraternal, procuraba, aunque en balde, desbancar a aquel". El Journal...: "robaba" al World sus dibujantes pagándoles grandes sueldos, aunque este se defendía con "procedimientos análogos" ${ }^{11}$.

¿Puede alguien confiar en esos periódicos? Los artículos publicados en La Época querían dejar claro a sus lectores que la prensa sensacionalista americana no merecía ninguna credibilidad. No le faltaba razón. Lástima que no fuese igualmente crítica con la información sobre la guerra publicada en sus páginas.

\section{Hemerotecografía}

Diario Evening Post

Diario Journal

Diario La Época.

Diario New York Times

Diario Herald

Diario World

\footnotetext{
11 "Los orígenes de la guerra", La Época, 22 de mayo de 1898.
} 